\title{
Incentive Contract in Supply Chain with Asymmetric Information
}

\author{
Yingsheng Su, ${ }^{1}$ Hongmei Guo, ${ }^{2}$ and Xianyu Wang ${ }^{2}$ \\ ${ }^{1}$ Statistics School, Southwestern University of Finance and Economics, Chengdu 611130, China \\ ${ }^{2}$ Business School, Sichuan University, Chengdu 610064, China \\ Correspondence should be addressed to Yingsheng Su; suys@swufe.edu.cn
}

Received 28 June 2013; Revised 20 November 2013; Accepted 18 December 2013; Published 5 January 2014

Academic Editor: Tinggui Chen

Copyright (c) 2014 Yingsheng Su et al. This is an open access article distributed under the Creative Commons Attribution License, which permits unrestricted use, distribution, and reproduction in any medium, provided the original work is properly cited.

\begin{abstract}
The supply chain always appears inefficient because of the different targets of members and information asymmetry, especially when upstream enterprises not only hide information about their effort levels, but also hide information about their technology level. The paper uses principal-agent theory and the theory of regulation to design the contract to realize the maximization of principal's profit on the condition that the contract satisfies the participant and incentive conditions of agent. As a result, it is obvious that the contract achieves the goal of control. In addition, it also can be concluded that the amount of rent that the manufacturer can obtain is up to the value of his information and the condition of his resource.
\end{abstract}

\section{Introduction}

Supply chain is a network which can put suppliers, manufacturers, distributors, retailers, and final users together, which is characterized by the integration of external resources for cooperation networks. Supply chain performance depends on the joint benefit of the enterprises [1]. However, the supply chain always appears inefficient because of the different targets of members and information asymmetry. Therefore, an important issue in supply chain management is how to establish the appropriate coordination mechanism for the independent enterprises in order to achieve the maximization of the overall profit of the supply chain [2-8].

Because of information asymmetry, the difficulty of coordination increases [9]. Many contracts and pieces of literature have studied the coordination of supply chain from perspective of principal-agent problem, while, at the same time, various aspects of coordination in supply chain have been studied too, such as pieces of literature [10-16].

In practice, the effort level of retailers can affect products' demand. Literature [17] puts the effort level and risk preference of decision-making of node enterprise into decisionmaking model and analyses their impact on the decision and cooperation of supply chain. The literature [18] investigates the issue of channel coordination for a supply chain facing stochastic demand that is sensitive to both sales effort and retail price. In the literature [19], a perishable product's supply chain consisting of a manufacturer and a retailer is considered; on the premise of retailer's effort and return price dependent demand, the mathematical models of quantity flexibility contract are established. The literature [20] analyses retailer's effort level's impact on supply chain revenue-sharing evolvement- contract and gain retailer's effort level's reaction function and its optimal value.

These pieces of literature, for example, literature [19], think that effort level of the upstream agents is private information which is the key to cause motivation. The profit of supply chain increases synchronously when the effort level of upstream enterprises increases, while, at the same time, the cost of effort level of upstream enterprises also increases. What is more, the increased cost of upstream enterprises may be much more than profit of upstream enterprises. Therefore, in order to maximize their own profits, efforts of downstream enterprises may be not in the appropriate level. So, an effective solution to the principal-agent problem between the upstream and downstream enterprises is to stimulate the upstream enterprises to improve their effort levels. However, we think that, in fact, upstream enterprises 
not only hide information about their effort levels, but also hide information about their technology level (or resource endowments). If the downstream enterprise has poor knowledge about distribution of technology level to the upstream enterprise, the upstream enterprise may obtain higher rent (e.g., supply chain distribution is carried out in accordance with the amount of resource input. If the downstream enterprise has vaguer understanding of the upstream firm's resource input, the upstream firm's transferring rent may be higher). Therefore, an effective solution to the agency problem between the upstream and downstream enterprises may need not only simulating the effort level of downstream firm, but also taking the effect of technology level to income distribution into account. This paper designs the incentive system based on the supply chain through two kinds of constraints, moral hazard and adverse selection.

\section{Assumptions of Model}

This paper considers that there are one seller and one manufacturer in a two-lever supply chain. The seller simulates the manufacturer that hides private information. In order to keep generality, Assumptions 5-7 are basic hypothesizes of general information economics. Assumptions 1-4 are the basis of our model.

Assumption 1. When he gets paid from consumers, the seller gives the manufacturer cost compensation $s \cdot C$ ( $s$ is compensation rate and $0<s<1$ ) and transferring payment $t$.

This assumption points out the characteristics of the decision-making. The profit of the manufacturer is made up with the payment of cost compensation and the transferring payment $t$. Therefore, the key motivation of the seller to the manufacturer is the design of $t$. It is a common assumption in incentive problem. For example, literature [20] uses the same assumption.

Assumption 2. There are moral hazard and adverse selection in motivation.

In contract, the manufacturer has his private information of technology, but the cost of the activity which is reduced cannot be observed by the seller. Cost function [21] can be written in the following form:

$$
C=(\beta-e) q+\alpha
$$

In this function, $\beta$ is a technical parameter (high $\beta$ means inefficient technical level). The seller does not know the $\beta$ of the manufacturer, but he knows that $\beta$ is a continuous parameter which belongs to $[\beta, \bar{\beta}] ; F(\cdot)$ means the absolutely continuous distribution function and its density is $f(\cdot)$; what is more, when $\beta \in[\beta, \bar{\beta}], f(\beta)>0$. In addition, the monotone hazard rate or log-concave $d[F(\beta) / f(\beta)] / d \beta \geq$ 0 . For most distributions, such as uniform distribution, normal distribution, logarithmic distribution, exponential distribution, and Laplace distribution, they all satisfy the condition of monotone hazard rate [21]. $e$ is the effort or cost reduction activities (the speed of cost reduction activity is decreasing). $e$ is related to the types of the manufacturer; in other words, $e=e(\beta)$. This cannot be observed by the seller. We can define $\psi(e)$ as the cost of effort and it satisfies $\psi^{\prime}(e)>0, \psi^{\prime \prime}(e)>0, \psi^{\prime \prime \prime}(e) \geq 0, \psi(\beta)=+\infty$. $q$ means production. $\alpha$ is the fixed cost which we standardize to zero. At this point, $c=(\beta-e)$ is not only the marginal cost of the manufacturer, but also the average cost of the manufacturer.

This assumption means that this paper involves two kinds of asymmetric information. Generally speaking, most of the pieces of literature about asymmetric information only involve a certain kind. For example, literature [22] provides quantity discount contract in which cost is private information (adverse selection). Literature [23] studies problem about moral hazard in warranty contract. However, a few pieces of literature study two kinds of asymmetric information. For example, literature [24] uses the principal-agent theory and studies the game between supplier and retailer in supply chain with two kinds of asymmetric information-adverse selection and moral hazard.

Assumption 3. The cost of the manufacturer is $C$ and the production is $q$; what is more, the cost and production can be verified. However, the seller cannot distinguish the various components of the cost.

This assumption indicates that the optimal incentive contract is based on the total cost and demand data. It is the extension of Assumption 2.

Assumption 4. Because the seller cannot observe $\beta, e$, when the seller designs the incentive contracts, he considers the design of $t$ through $\widehat{\beta}$ which is announced by the manufacturer.

Assumption 5. If the contract cannot guarantee the lowest expected utility of the manufacturer, the manufacturer can refuse to produce.

This assumption forces the seller to keep to the "participation" constraint of the manufacturer. It can be seen in many pieces of literature about contract design, such as pieces of literature [18-20], and literature [22]. We can define $U$ as the expected utility of the manufacturer and standardize the lowest expected utility to zero. $U \geq 0$ is the rent of the manufacturer or surplus.

Assumption 6. The risks of the seller and manufacturer are neutral.

This assumption not only can decrease the computational difficulty, but also does not lose generality.

Assumption 7. In order to discuss easily, we can define the relationship of the total production and price as

$$
q=a-b p \text {. }
$$

Based on these assumptions, the seller is the designer and executor of the contract. The seller can design the transfer 
payment $t$ to motivate the manufacturer, while, at the same time, the action of the manufacturer chooses the lever of effort $e$ and announces the level of technical parameter $\widehat{\beta}$. The design of incentive system has the following game order and strategies.

(1) The seller designs the contract, which is the function of the total output, cost, and $\widehat{\beta}$.

(2) When the manufacturer knows the content of the contract, the manufacturer needs to decide whether to accept the contract, to choose the lever of effort, and to announce the level of $\widehat{\beta}$.

(3) The seller observes the total production, cost, and $\widehat{\beta}$.

(4) According to the observations, the seller executes the contract.

\section{Model Analysis and Solution}

3.1. Conditions of Participation and Incentive for the Manufacturer. According to Assumptions 2-5, when the manufacturer announces the technical parameter $\widehat{\beta}$, the transfer payment that is received by the manufacturer is $t(\widehat{\beta})$, and the utility of the manufacturer is the function of real technical parameter $\beta$ and announced technical parameter $\widehat{\beta}$ :

$$
u(\beta, \widehat{\beta})=t(\widehat{\beta})-(1-s) c(\widehat{\beta}) q-\psi(\beta-c(\widehat{\beta})) .
$$

According to Assumption 6, the contract must reach the lowest expected utility level of the manufacturer, or the manufacturer will refuse to cooperate. So,

$$
u(\beta, \widehat{\beta}) \geq 0
$$

Formula (4) embodies the manufacturer's participation constraint. When the seller designs contract, he must keep the "participation" constraint of the seller.

In order to motivate the manufacturer to announce the real technical parameter, the design of the contract must satisfy the following conditions.

For all $\beta_{1}, \beta_{2} \in[\beta, \bar{\beta}]$, if the manufacturer claims that his technology level is higher than the actual level, the seller will pay more rent to motivate. Therefore, in order to stimulate the manufacturer to announce the true technology level, the seller develops the following rules:

$$
\begin{aligned}
& t\left(\beta_{1}\right)-(1-s) c\left(\beta_{1}\right) q-\psi\left(\beta_{1}-c\left(\beta_{1}\right)\right) \\
& \quad \geq t\left(\beta_{2}\right)-(1-s) c\left(\beta_{2}\right) q-\psi\left(\beta_{1}-c\left(\beta_{2}\right)\right), \\
& t\left(\beta_{2}\right)-(1-s) c\left(\beta_{2}\right) q-\psi\left(\beta_{2}-c\left(\beta_{2}\right)\right) \\
& \quad \geq t\left(\beta_{1}\right)-(1-s) c\left(\beta_{1}\right) q-\psi\left(\beta_{2}-c\left(\beta_{1}\right)\right) .
\end{aligned}
$$

Formula (5) may transform to

$$
\int_{\beta_{1}}^{\beta_{2}} \int_{c\left(\beta_{1}\right)}^{c\left(\beta_{2}\right)} \psi^{\prime \prime}(y-x) \mathrm{d} x \mathrm{~d} y \geq 0
$$

Form Assumption 2, we know that $\psi^{\prime \prime}(\cdot)>0$. So formula (6) indicates that $c(\beta)$ is the nondecreasing function of $\beta$; in other words, $\dot{c}(\beta) \geq 0$.

If the manufacturer chooses the best $\widehat{\beta}$ in order to maximize the rent, we can define $U(\beta)=\max _{\widehat{\beta}} u(\beta, \widehat{\beta})$ as the rent of the manufacturer, and $\widehat{\beta}$ is based on the real technical parameter $\beta$; in other words, $\widehat{\beta}=\widehat{\beta}(\beta)$. Then the maximum first derivative of formula (3) to $\beta$ is zero. We use the envelope theorem to maximize formula (3) and announce that the technical parameter $\widehat{\beta}=\beta$; we can get that

$$
\dot{U}(\beta)=-\psi^{\prime}(\beta-c(\beta)) \text {. }
$$

If you meet the first-order condition, and $c(\beta)$ is nondecreasing, then formula (7) is not only the necessary condition, but also the sufficient condition of both formulas of (5), thereby it can satisfies the incentive requirements. Then from "participation" condition (4), we know that $U(\beta) \geq 0$. Because the rent of the seller which is designed to motivate is cost, and from the formula (7), we know that $\dot{U}(\beta) \leq 0$. So, the seller defines $U(\bar{\beta})=0$. We can obtain from formula (7)

$$
U(\beta)=\int_{\beta}^{\bar{\beta}} \psi^{\prime}(e(\widetilde{\beta})) \mathrm{d} \widetilde{\beta} .
$$

So, the expected transfer rent of the seller is

$$
\begin{aligned}
\int_{\underline{\beta}}^{\bar{\beta}} U(\beta) \mathrm{d} F(\beta) & =\int_{\underline{\beta}}^{\bar{\beta}} \int_{\beta}^{\bar{\beta}} \psi^{\prime}(e(\widetilde{\beta})) \mathrm{d} \widetilde{\beta} \mathrm{d} F(\beta) \\
& =\int_{\underline{\beta}}^{\bar{\beta}} \frac{F(\beta)}{f(\beta)} \psi^{\prime}(e(\beta)) \mathrm{d} F(\beta) .
\end{aligned}
$$

The second equation uses integration by parts. Therefore, we can get the following incentive compatibility constraints:

$$
\begin{gathered}
\int_{\underline{\beta}}^{\bar{\beta}} U(\beta) \mathrm{d} F(\beta)=\int_{\underline{\beta}}^{\bar{\beta}} \frac{F(\beta)}{f(\beta)} \psi^{\prime}(e(\beta)) \mathrm{d} F(\beta), \\
\dot{c}(\beta) \geq 0 .
\end{gathered}
$$

3.2. The Goal of the Seller. The seller can decide $t(\cdot)$ and maximize its expected profit according to the observed contract parameters $c(\cdot), q(\cdot)$ (the cost of the seller can be standardized to 0$)$. Consider

$$
\max _{\{C(\cdot), t(\cdot), q(\cdot)\}} \int_{\underline{\beta}}^{\bar{\beta}}[p(q) \cdot q-s \cdot c \cdot q-t] \mathrm{d} F(\beta) .
$$

Put formulas (1) and (2) into formula (12), we can get

$$
\begin{gathered}
\max _{\{e(\cdot), q(\cdot), U(\cdot)\}} \int_{\underline{\beta}}^{\bar{\beta}}[p(q) \cdot q-(\beta-e(\beta)) \cdot q-\psi(e(\beta)) \\
-U(\beta)] \mathrm{d} F(\beta) .
\end{gathered}
$$

At the same time, when the seller designs the contract, he is also restricted by the incentive compatibility constraints, namely, (10) and (11) constraints. 
3.3. Determination of the Contract. Put formula (10) into formula (13), we can get the optimal planning of the seller:

$$
\begin{aligned}
\max _{\{e(\cdot), q(\cdot), U(\cdot)\}} \int_{\underline{\beta}}^{\bar{\beta}}[p(q) \cdot q-(\beta-e(\beta)) \cdot q \\
\left.\quad-\psi(e(\beta))-\frac{F(\beta)}{f(\beta)} \psi^{\prime}(e(\beta))\right] \mathrm{d} F(\beta) .
\end{aligned}
$$

The condition of constraint is

$$
\dot{e}(\beta) \leq 1
$$

Here, formula (15) is based on the $C(\beta)=(\beta-e(\beta)) \cdot q$ of Assumption 2 and formula (11).

From Assumption 2, we can know that $\psi^{\prime \prime \prime}(e) \geq 0$, so the integrand function of formula (14) is concave. Let us ignore the constraint of formula (15); find the first-order condition of $e(\cdot), q(\cdot)$ from the integral term of formula (14) and we can obtain

$$
\begin{gathered}
q-\psi^{\prime}(e(\beta))-\frac{F(\beta)}{f(\beta)} \psi^{\prime \prime}(e(\beta))=0, \\
p(q)-(\beta-e(\beta))+\dot{p}(q) q=0 .
\end{gathered}
$$

Through formulas (2) and (17), we can get

$$
q=\frac{a}{2}-\frac{b}{2}(\beta-e(\beta))
$$

Then

$$
\dot{q}(\beta)=-\frac{b}{2}((\beta-e(\beta)))_{\beta}^{\prime}=-\frac{b}{2} \dot{c}(\beta) \leq 0
$$

Find the derivate of $\beta$ from formula (16), we can get

$$
\begin{gathered}
\dot{q}(\beta)-\psi^{\prime \prime}(e(\beta)) \cdot \dot{e}(\beta)-\frac{d}{d \beta}\left[\frac{F(\beta)}{f(\beta)}\right] \cdot \psi^{\prime \prime}(e(\beta)) \\
-\frac{F(\beta)}{f(\beta)} \cdot \psi^{\prime \prime \prime}(e(\beta)) \cdot \dot{e}(\beta)=0 .
\end{gathered}
$$

So

$$
\dot{e}(\beta)=-\frac{0.5 b \cdot \dot{c}_{\beta}+\psi^{\prime \prime}(e(\beta)) \cdot\{d[F(\beta) / f(\beta)] / d \beta\}}{\psi^{\prime \prime}(e(\beta))+\psi^{\prime \prime \prime}(e(\beta)) \cdot[F(\beta) / f(\beta)]} .
$$

From Assumption 2 and formula (19), we can know that the denominator of formula (21) is positive. Then through Assumption 2, the monotone risk rate is positive, and we know that the molecule of formula (21) is positive. So,

$$
\dot{e}(\beta) \leq 0_{\circ} .
$$

It satisfies the condition of formula (20).
From formulas (16) and (17), we can get $e^{*}(\beta)$ and $q^{*}(\beta)$; the rent of the manufacturer and transfer payment is

$$
\begin{gathered}
U^{*}(\beta)=\int_{\beta}^{\bar{\beta}} \psi^{\prime}\left(e^{*}(\widetilde{\beta})\right) \mathrm{d} \widetilde{\beta}, \\
t^{*}(\beta)=U^{*}(\beta)+\psi\left(e^{*}(\beta)\right)+(1-s) C(\beta) .
\end{gathered}
$$

According to Assumption 2, we know that the average cost $c=C / q$ is a strictly increasing function, so the inverse function exists as $\beta=\beta^{*}(c)$. Put this function into formula (24) we can get that the optimal transfer payment is the function of observed average cost:

$$
\begin{aligned}
t^{*}(c)= & U^{*}\left(\beta^{*}(c)\right)+\psi\left(e^{*}\left(\beta^{*}(c)\right)\right) \\
& +(1-s) c \cdot\left(\frac{a}{2}-\frac{b}{2}\left(\beta^{*}(c)-e\left(\beta^{*}(c)\right)\right)\right) .
\end{aligned}
$$

When $s=1$, the optimal contract which can be performed is

$$
T(\widehat{\beta}, c)=U^{*}\left(\widehat{\beta}^{*}(c)+\psi\left(e^{*}\left(\widehat{\beta}^{*}(c)\right)\right)\right) .
$$

\section{Propositions Related to the Supply Chain}

Proposition 8. The best incentive program can be performed through the contract which is defined by formula (27).

When $s=1, t(\cdot)$ is a convex function, so you can use it to replace its tangent cluster. These tangents mean the contract menu of linear function of cost

$$
t^{*}(\widehat{\beta}, c)=t^{*}(\widehat{\beta})-\psi^{\prime}\left(e^{*}(\widehat{\beta})\right) \cdot\left(c-c^{*}(\widehat{\beta})\right) .
$$

Formula (27) will induce the manufacturer to tell the truth $(\widehat{\beta}=\beta)$ and can induce the appropriate effort level. When the manufacturer faces the menu of linear contracts, the optimal planning of the seller is

$$
\begin{aligned}
\max _{\{\widehat{\beta}, e\}}\left\{t^{*}(\widehat{\beta})-\psi^{\prime}\left(e^{*}(\widehat{\beta})\right)\right. \\
\left.\cdot\left(\beta-e-\widehat{\beta}+e^{*}(\widehat{\beta})\right)-\psi(e)\right\} .
\end{aligned}
$$

We can get the first-order condition of $\widehat{\beta}$ and $e$ from formula (28) and we can find that $e=e^{*}(\widehat{\beta}), \widehat{\beta}=\beta$.

Proposition 9. The rent of the manufacturer is due to the value of the private information.

If the seller knows the type of $\beta$ from the manufacturer, according to Assumption 6, as long as the contract can guarantee the lowest expected utility level of the manufacturer, the manufacturer will cooperate, so the transfer rent of the seller to the manufacturer can be $U(\beta)=0$. At this point, the rent of the manufacturer is 0 . However, in the scene of asymmetric information, the seller does not know the $\beta$ of the manufacturer, but he knows that $\beta$ is a continuous parameter which belongs to $[\beta, \bar{\beta}]$. In order to ensure that the manufacturer will cooperate, the seller needs to take the 
type of $\bar{\beta}$ into consideration and the transfer rent is $U(\bar{\beta})=$ 0 . Therefore, from (8) formula, we can know that the rent which the manufacturer will receive is $U(\beta)=\int_{\beta}^{\bar{\beta}} \psi^{\prime}(e(\widetilde{\beta})) d \widetilde{\beta}$. From the above analysis, we can know that the reason why the manufacturer can receive the rent $U(\beta)$ is that he has private information. So, on the other side, $U(\beta)$ is the value of information $\beta$.

Proposition 10. If the resource endowment of the manufacturer is better (the technical level is higher), the effort will be increasing.

Form formula (22), we know that the effort of the manufacturer is increasing as $\beta$ decreases.

Proposition 11. If the resource endowment of the manufacturer is better, the production will be increasing.

Form formula (19), we know that the production of the manufacturer is increasing as $\beta$ decreases.

Proposition 12. The better the resource endowment of the manufacturer is, the greater the incentive intensity of the seller will be.

When $s=1$, by finding the derivative of formula (25), we can get

$$
\frac{\mathrm{d} t}{\mathrm{~d} \beta}=-\dot{\psi}\left(\beta^{*}(c)-c\right) \cdot \dot{c}(\beta)<0 .
$$

So, if $\beta$ is lower, the transfer payment will be more.

Proposition 13. The better the resource endowment of the manufacturer is, the greater the revenue from supply chain will be.

Putting formulas (2) and (18) into the function $\pi=p(q) \cdot q$ of the revenue chain and finding the derivative of $\beta$ in $\pi$, we can get

$$
\dot{\pi}(\beta)=-\frac{b^{2}}{4}(\beta-e(\beta)) \cdot \dot{c}(\beta)<0
$$

Proposition 14. When the tax rate increases, the production of the manufacturer will reduce.

Finding the derivative of $\lambda$ in the formula (18), we can get

$$
\dot{q}(\lambda)=-\frac{b}{2}(\beta-e(\beta))<0 .
$$

\section{Numerical Example}

In the agrifood supply chain, agricultural cooperatives provide green agricultural products to supermarket. The cost of green agricultural products from agricultural cooperatives can be decreased by agricultural cooperatives effort; however, this effort is somewhat exhausting. Let us give some specific expression.
TABLE 1: Comparison with profit when a different $\widehat{\beta}$ is announced by the manufacturer.

\begin{tabular}{lcccc}
\hline$\beta$ & $e$ & $\widehat{\beta}$ & $e^{*}(\widehat{\beta})$ & $U^{*}$ \\
\hline 2.8 & 1.4 & 2.8 & 1.4 & 3.744 \\
2.8 & 1.4 & 3 & 1 & 2.112 \\
2.8 & 1.4 & 2.6 & 1.8 & 1.344 \\
\hline
\end{tabular}

Demand function is

$$
q=84-24 p
$$

Effort's cost function is

$$
\psi(e)=2 e^{3}
$$

Continuous density function is

$$
f(\beta)=\left\{\begin{array}{ll}
\frac{1}{2} & 2 \leq \beta \leq 4 \\
0 & \text { other }
\end{array} .\right.
$$

Let $s=1, \beta=2.8$. If we execute the linear contract expressed by formula (27) we can get agricultural cooperatives' profit in different circumstances as follows.

In Table 1, it is easily concluded that agricultural cooperatives can get optimal profit when agricultural cooperatives announce the true technology level and work as optimal effort lever.

\section{Conclusion}

This paper discusses the incentive system design between the seller and manufacturer with two types of information constraints. According to Proposition 8 of this paper, the paper provides linear contract. At the same time, by Proposition 9 we find that in the supply chain one of the major reasons why the principal enterprise provides rents, which is higher than the reservation utility of agent enterprise, to agent enterprise is that agent enterprises have some private information. We can also call this kind of rent as value of information.

Known from Proposition 12, when the agent's resource endowment is higher, the strength of motivation to the principal is greater. At the same time, the rent which the agent can obtain is more. In addition, known from Proposition 13, when the resource endowment of enterprises in the supply chain is higher, the benefit of the whole chain will be greater. Therefore, the resource situation of enterprises in this supply chain not only affects the distribution of all members, but also affects the benefits of the supply chain.

Further study is the investment incentive which cannot be contracted between core firms and nondominated firms in the supply chain.

\section{Conflict of Interests}

The authors declare that there is no Conflict of Interests regarding the publication of this paper. 


\section{Acknowledgment}

This work was partly supported by Soft Science Research Project of Sichuan Province (2013ZR0031).

\section{References}

[1] K. Zimmer, "Supply chain coordination with uncertain just-intime delivery," International Journal of Production Economics, vol. 77, no. 1, pp. 1-15, 2002.

[2] F. S. Oliveira, C. Ruiz, and A. J. Conejo, "Contract design and supply chain coordination in the electricity industry," European Journal of Operational Research, vol. 227, no. 3, pp. 527-537, 2013.

[3] S. Saha, "Supply chain coordination through rebate induced contracts," Transportation Research E, vol. 50, pp. 120-137, 2013.

[4] E. Cao, C. Wan, and M. Y. Lai, "Coordination of a supply chain with one manufacturer and multiple competing retailers under simultaneous demand and cost disruptions," International Journal of Production Economics, vol. 141, no. 1, pp. 425-433, 2013.

[5] Y. Duan, J. Huo, Y. Zhang, and J. Zhang, "Two level supply chain coordination with delay in payments for fixed lifetime products," Computers \& Industrial Engineering, vol. 63, no. 2, pp. 456-463, 2012.

[6] G. P. Cachon, "Supply chain coordination with contracts," Working Paper, University of Pennsylvania, 2003.

[7] Y. Su, J. Lu, and D. Shi, "Incentive contract in supply chain based on control of cash flow," International Journal of Advancements in Computing Technology, vol. 4, pp. 115-121, 2012.

[8] B. A. Pasternack, "Optimal pricing and return policies for perishable commodities," Marketing Science, vol. 27, no. 1, pp. 131-132, 2008.

[9] A. A. Tsay, "The quantity flexibility contract and suppliercustomer incentives," Management Science, vol. 45, no. 10, pp. 1339-1358, 1999.

[10] G. D. Eppen and A. V. Iyer, "Backup agreements in fashion buying - the value of upstream flexibility," Management Science, vol. 43, no. 11, pp. 1469-1484, 1997.

[11] X. Guan and M. Liu, "Coordination in the decentralized assembly system with dual supply modes," Discrete Dynamics in Nature and Society, vol. 2013, Article ID 381987, 9 pages, 2013.

[12] F. Chen, "Echelon reorder points, installation reorder points, and the value of centralized demand information," Management Science, vol. 44, no. 12, pp. S221-S234, 1998.

[13] H. L. Lee and S. Whang, "Information sharing in a supply chain," International Journal of Technology Management, vol. 20, no. 3, pp. 373-387, 2000.

[14] H. L. Lee, V. Padmanabhan, and S. Whang, "Information distortion in a supply chain: the bullwhip effect," Management Science, vol. 43, no. 4, pp. 546-558, 1997.

[15] G. P. Cachon and M. Fisher, "Supply chain inventory management and the value of shared information," Management Science, vol. 46, no. 8, pp. 1032-1048, 2000.

[16] G. P. Cachon and M. A. Lariviere, "Contracting to assure supply: how to share demand forecasts in a supply chain," Management Science, vol. 47, no. 5, pp. 629-646, 2001.

[17] L. Li, "Information sharing in a supply chain with horizontal competition," Management Science, vol. 48, no. 9, pp. 1196-1212, 2002.

[18] Y. He, X. Zhao, L. Zhao, and J. He, "Coordinating a supply chain with effort and price dependent stochastic demand,"
Applied Mathematical Modelling. Simulation and Computation for Engineering and Environmental Systems, vol. 33, no. 6, pp. 2777-2790, 2009.

[19] Y. Su, D. Shi, and J. Wu, "Dynamic incentive policy in supply chain," ICIC Express Letters, vol. 5, no. 11, pp. 4155-4161, 2011.

[20] X. Wang, X. Wang, and Y. Su, "Wholesale-price contract of supply chain with information gathering," Applied Mathematical Modelling, vol. 37, no. 6, pp. 3848-3860, 2013.

[21] J. J. Laffont and J. Tirole, $A$ Theory of Incentives in Procurement and Regulation, Shanghai People's Publishing House, Shanghai, China, 2004, (Chinese).

[22] C. J. Corbett and X. De Groote, "Supplier's optimal quantity discount policy under asymmetric information," Management Science, vol. 46, no. 3, pp. 444-450, 2000.

[23] G. L. Priest, "The background to products liability," European Journal of Marketing, vol. 15, no. 2, pp. 4-9, 1981.

[24] P. J. Agrell, R. Lindroth, and A. Norrman, "Risk, information and incentives in telecom supply chains," International Journal of Production Economics, vol. 90, no. 1, pp. 1-16, 2004. 


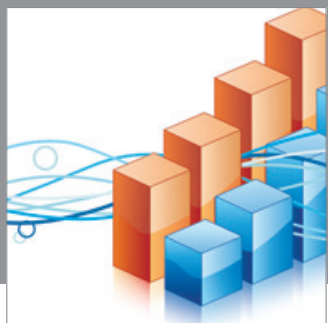

Advances in

Operations Research

mansans

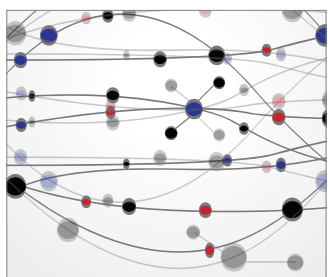

The Scientific World Journal
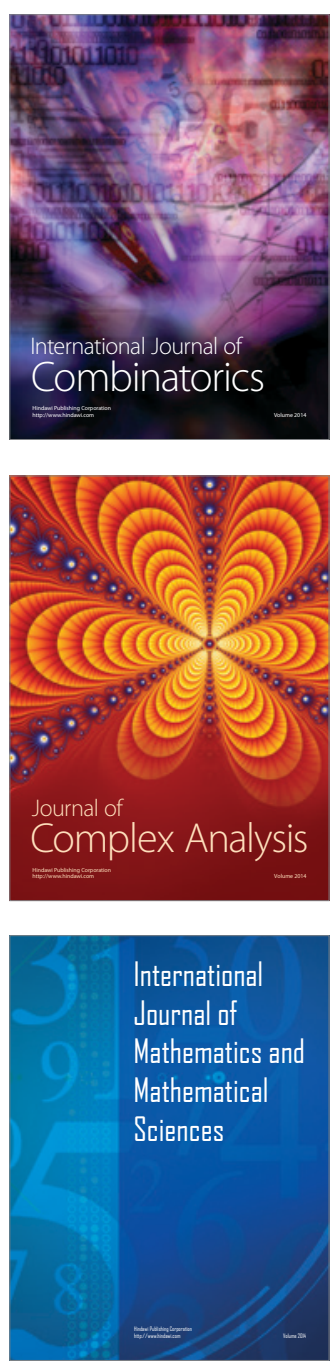
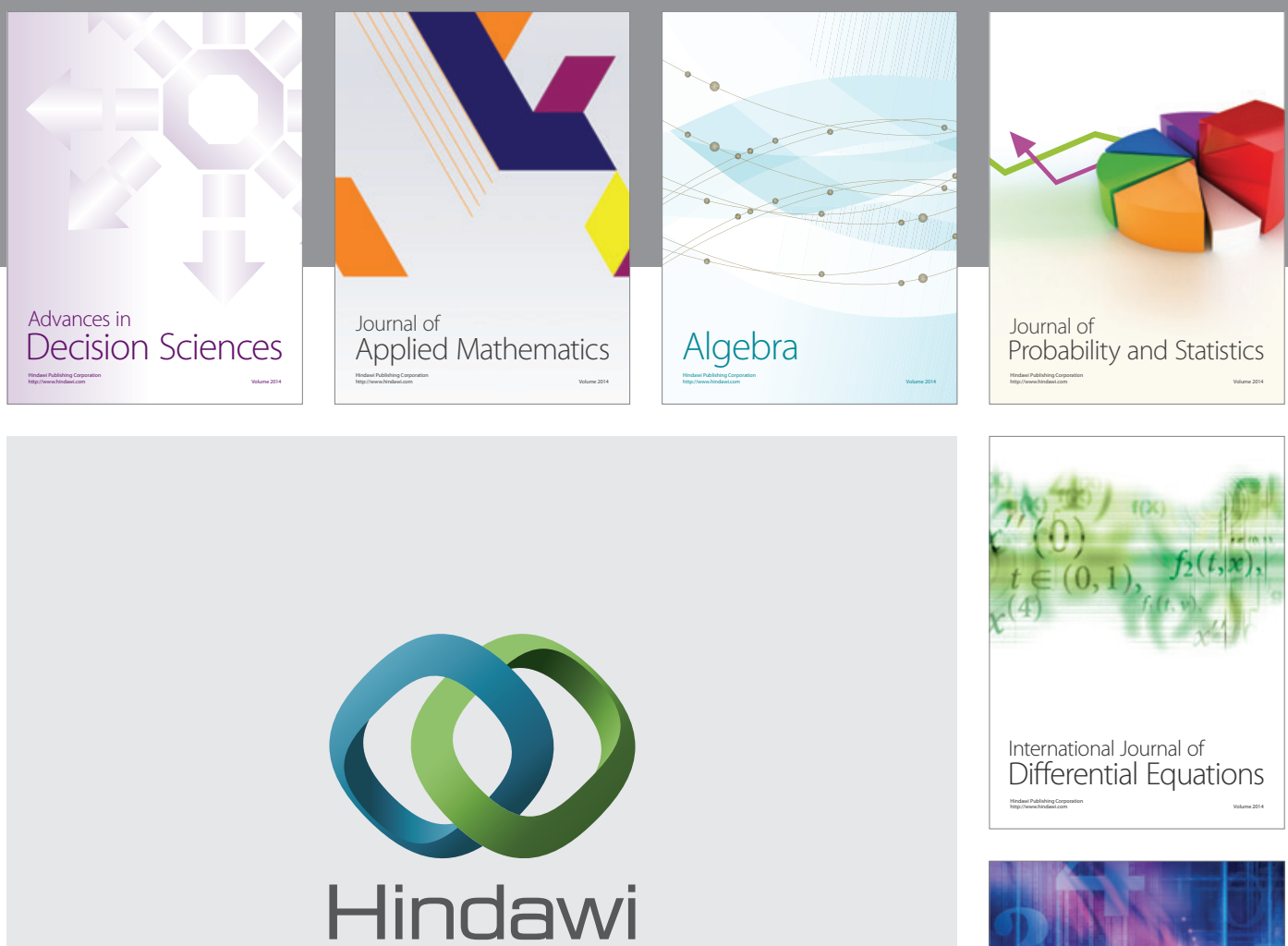

Submit your manuscripts at http://www.hindawi.com
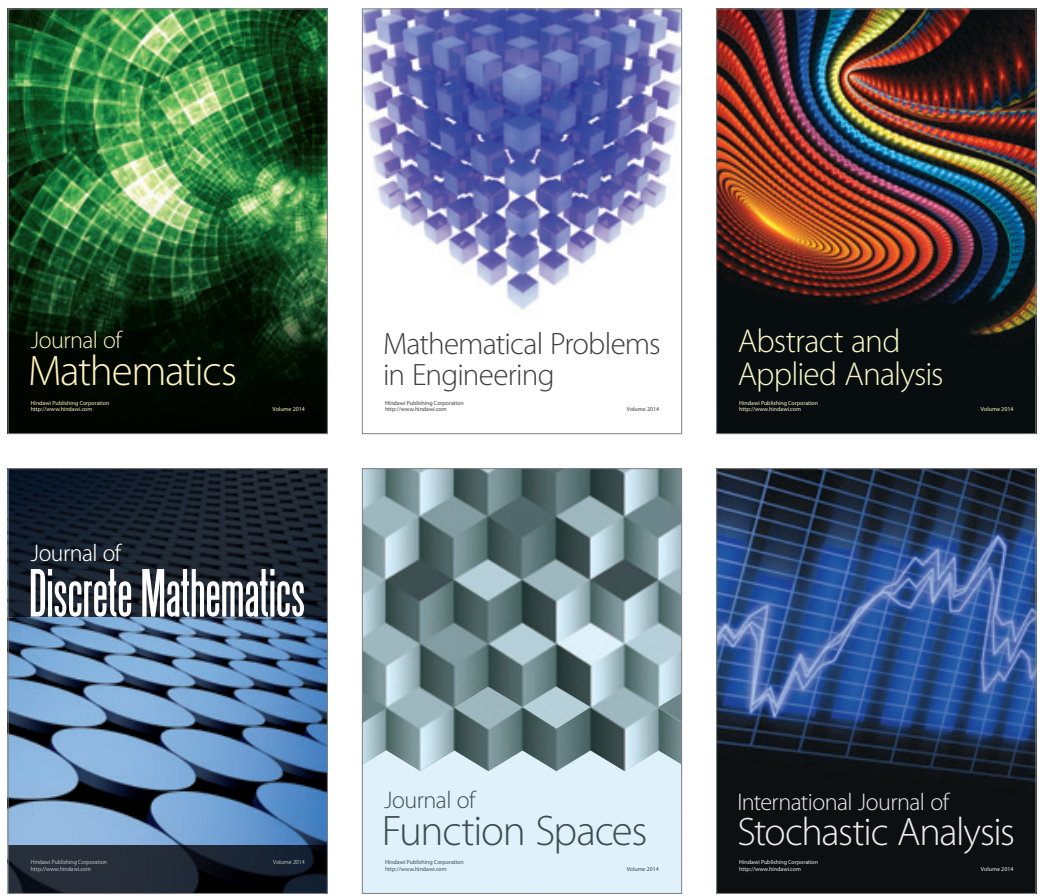

Journal of

Function Spaces

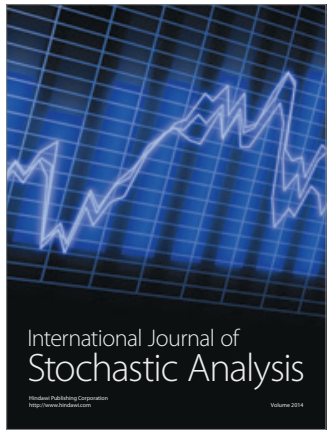

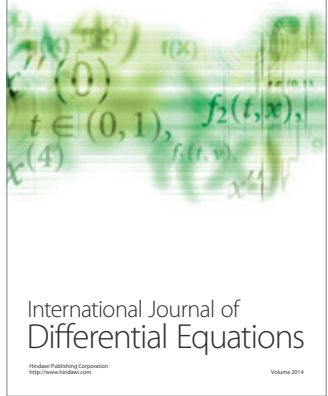
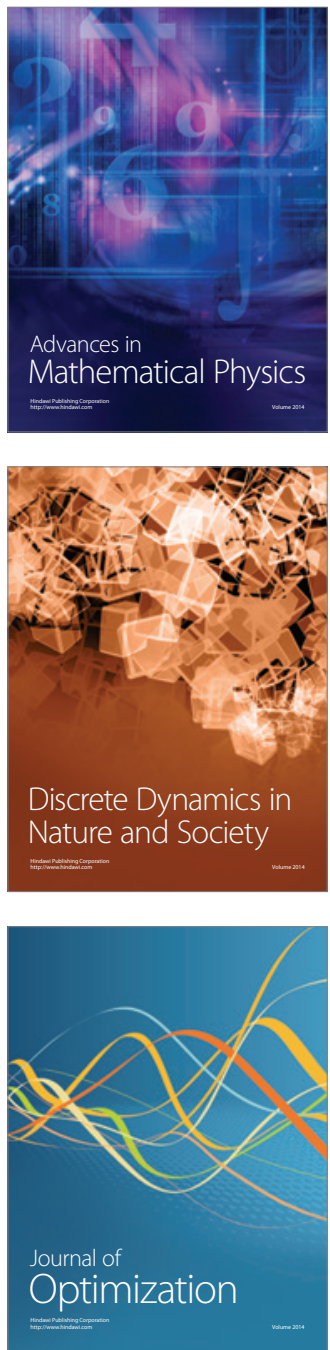